\title{
Interacción imagen fotográfica-texto como estrategia de comunicación política en Instagram durante la campaña electoral del 28A de 2019 en España
}

\author{
Photo-text interaction as a political communication \\ strategy on Instagram during the campaign for the \\ Spanish election of 28 April 2019
}

\author{
Alejandra Tirado-García; Hugo Doménech-Fabregat
}

Cómo citar este artículo:

Tirado-García, Alejandra; Doménech-Fabregat, Hugo (2021). “Interacción imagen fotográfica-texto como estrategia de comunicación política en Instagram durante la campaña electoral del 28A de 2019 en España". Profesional de la información, v. 30, n. 2, e300223.

https://doi.org/10.3145/epi.2021.mar.23

Artículo recibido el 22-10-2020

Aceptación definitiva: 20-11-2020

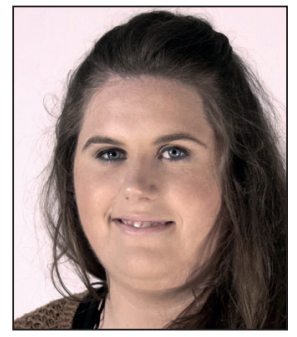
Alejandra Tirado-García $\triangle$ https://orcid.org/0000-0001-5947-7215
Universitat Jaume I de Castelló Facultat de Ciències Humanes i Socials Dpto. de Ciències de la Comunicació Avda. Vicent Sos Baynat, s/n. 12071 Castelló de la Plana, España tiradoa@uji.es

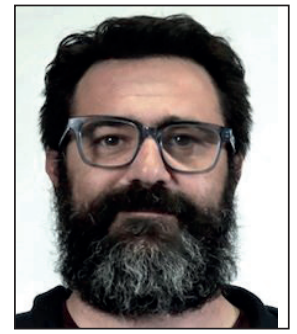
Hugo Doménech-Fabregat
https://orcid.org/0000-0002-1247-9587
Universitat Jaume I de Castelló
Facultat de Ciències Humanes i Socials
Dpto. de Ciències de la Comunicació
Avda. Vicent Sos Baynat, s/n.
12071 Castelló de la Plana, España
hdomenec@uji.es

Resumen

En los últimos años la red social de intercambio fotográfico Instagram se ha convertido en un importante canal en las estrategias de comunicación de los actores políticos tanto del panorama nacional como internacional. Este artículo se aproxima al estudio de Instagram desde una perspectiva diferente con respecto a lo estudiado hasta la fecha: analizar la gestión estratégica del binomio imagen fotográfica-texto en esta red social en el contexto de la comunicación política. El diseño metodológico consta de una aproximación de naturaleza cuantitativa basada en el análisis de contenido. A partir de un modelo de análisis de elaboración propia, se han revisado tres categorías asociadas a los parámetros centrales de la imagen fotográfica, el texto y su interrelación durante la campaña electoral española del 28A (del 12 al 26 de abril de 2019, ambos inclusive). La selección de este período temporal se debe a que se trata de un momento que resulta clave en la esfera política al despertar un gran interés social y consumo informativo entre los ciudadanos y, en consecuencia, una mayor preocupación de los partidos por la comunicación estratégica de su acción política. Integran la muestra 314 posts publicados por los cinco principales partidos españoles y sus respectivos líderes, candidatos a la presidencia del Gobierno. Los resultados muestran que la complementariedad domina como principal forma de interacción entre ambos componentes (imagen-texto), si bien existe una presencia significativa de tipos de interacción problemáticos como la redundancia o la independencia. Pese a la progresiva profesionalización del uso político de la red social, se detecta que no se consigue un aprovechamiento potencialmente efectivo del tándem icono verbal en el uso de Instagram como vértice estratégico de comunicación política.

Palabras clave

Comunicación política; Medios sociales; Redes sociales; Instagram; Estrategias; Interacción; Imágenes fotográficas; Texto; Campañas electorales; Partidos políticos; España. 


\begin{abstract}
In recent years, Instagram as a social network for photo exchange has become an important channel in the communication strategies of political actors at both the national and international level. This article studies Instagram from a differential perspective from previous studies by analyzing the strategic management of the photo-text binomial on this social network within the context of political communication. The methodological design of this research consists of a quantitative approach based on content analysis. Relying on a model of analysis developed by us, we revised three categories associated with the central parameters of the photographic image, the text, and their interrelationship during the campaign for the Spanish election of 28 April (dated between the 12 and 26 April 2019, both inclusive). The selection of this period is due to the belief that this is a key moment in the political sphere because it invoked great social interest and information consumption and, consequently, greater concern from the parties about the strategic communication of their political actions. The sample comprised 314 posts published by the five main Spanish parties and their respective leaders, candidates for the Government's Presidency. The results reveal that complementarity dominates as the main form of interaction between the two components (image and text), albeit with a significant presence of problematic interaction types such as redundancy or independence. Despite the progressive professionalization of the political use of social networks, it was found that the potentially effective use of the verbal-icon tandem is not currently applied on Instagram as a strategic approach for political communication.
\end{abstract}

\title{
Keywords
}

Political communication; Social media; Social networking sites; Instagram; Strategies; Interaction; Photographic images; Texts; Election campaigns; Political parties; Spain.

\section{Financiación}

Este trabajo está vinculado al proyecto "Comunicación política y redes sociales en campaña electoral: Impacto y parámetros de uso de Facebook e Instagram en España (UJI-B2017-55)", financiado por la Universitat Jaume I (Plan promoción de la investigación 2017).

\section{Introducción}

Si Twitter se había consagrado en la década anterior como la red social de referencia en la comunicación política digital, en los últimos años Instagram ha irrumpido con especial empuje. Los actores políticos del panorama internacional (Filimonov; Russmann; Svensson, 2016; Lalancette; Raynauld, 2017) y nacional (Quevedo-Redondo; Portalés-Oliva, 2017; Marcos-García; Alonso-Muñoz, 2017; López-Rabadán; Doménech-Fabregat, 2018), en un contexto en que predomina la espectacularización de la política (Pellisser-Rosell; Pineda, 2014; Pérez-Curiel; García-Gordillo, 2020), han encontrado en esta plataforma un canal potenciador de temas y recursos expresivos impactantes en el mensaje político (Montagut; Carrillo, 2017). La importancia de la red social Instagram en comunicación política ha sido progresiva y ha pasado de tener una función complementaria a Twitter (López-Meri; Marcos-García; Casero-Ripollés, 2017) a convertirse en uno de los principales canales que los equipos de comunicación utilizan en sus estrategias comunicativas (Slimovich, 2020).

Pese a que Instagram es una red social de trayectoria breve y con una dieta mediática diferente a la de otros grupos de la sociedad (Velert, 2020), la plataforma empieza a tomar relevancia como vehículo de la comunicación política. Durante las elecciones presidenciales de Estados Unidos en 2016, todos los principales partidos candidatos a las primarias usaron Instagram para promover su mensaje (NewsWhip, 2016; Sander, 2015); y a nivel mundial, más del 70\% de los líderes de los países de las Naciones Unidas tienen presencia en esta red social (Burson-Marsteller, 2017). Por parte de la ciudadanía, estudios recientes (Parmelee; Roman, 2019) demuestran que los usuarios que siguen a los líderes políticos en Instagram lo hacen principalmente por motivos informativos y de orientación, lo que puede observarse como un reflejo de que esta red social se considera un espacio importante para la información política.

Instagram apareció en octubre de 2010 como un híbrido entre el estilo interactivo de redes consolidadas como Facebook y Twitter y el contenido fotográfico de Flickr (López-Rabadán; Doménech-Fabregat, 2018) y, tras nueve años de crecimiento en su actividad, en 2018 registraba 300 millones de publicaciones diarias (WeAreSocial, 2018). Instagram se ha convertido en la sexta red en popularidad a nivel mundial con 1.000 millones de usuarios activos, un $25 \%$ más que en 2018, por detrás de Facebook o WhatsApp, entre otras, con 2.271 y 1.500 millones de usuarios respectivamente, y por encima de Twitter, con 326 millones, que se encuentra actualmente en fase de declive (WeAreSocial, 2019). En España, Instagram se consolida en la cuarta posición del ranking de las redes sociales más activas dado su elevado crecimiento en los últimos años que alcanzó los 13 millones de usuarios en 2017 (WeAreSocial, 2018). El 90\% de los usuarios de la plataforma a nivel mundial tiene un perfil marcadamente joven -menos de 35 años- (Selva-Ruiz; Caro-Castaño, 2017), si bien cabe destacar una progresiva incorporación de usuarios maduros -entre 55 y 65 años- (Relaño, 2016), datos que evidencian la posición de centralidad que ha alcanzado esta red social.

En el campo de la comunicación política, Instagram permite a los líderes generar un mensaje visual de gran impacto 
viral que posibilita una interacción natural y cercana con la ciudadanía, en gran parte, por su facilidad de uso a través del móvil. La potencia espectacular de la imagen digital y la capacidad de distribución viral son, entre otros, los motivos que llevan a los actores políticos a profesionalizar el uso político de esta red social (López-García, 2017), especialmente durante las campañas electorales, período en el que las imágenes influyen directamente en la forma en la que el votante valora e interpreta su mensaje (Schill, 2012). Pérez-Curiel y García-Gordillo (2020) hacen referencia a este hecho justificándolo en la potencial capacidad de las nuevas narrativas digitales para agudizar, a imagen y semejanza del debate televisivo, las emociones, los conflictos y los escándalos.

En un contexto de entretenimiento como el actual en el que se promociona la publicación de determinados aspectos de la vida privada de los líderes, estos perciben la capacidad que ofrece Instagram para generar una comunicación intensamente personalizada y con un gran componente emotivo ideológico (Quevedo-Redondo; Portalés-Oliva, 2017). Según Annunziata, Ariza y March, en la actualidad se da un tipo de vínculo representativo

"que se estructura sobre la base de una identificación anticarismática entre representantes y representados, y que se manifiesta en la presentación de los primeros como personas comunes" (Annunziata; Ariza; March, 2018, p. 62),

de forma que los políticos se presentan como hombres capaces de compartir las experiencias singulares de la ciudadanía (Slimovich, 2020).

En este sentido, la presente investigación se aproxima al estudio de Instagram en el campo de la comunicación política desde una perspectiva muy concreta: analizar la gestión estratégica del binomio imagen fotográfica-texto en Instagram como estrategia de comunicación política actual. Se trata así de un enfoque analítico diferencial dado que, hasta la fecha, las investigaciones realizadas se han centrado en el estudio de la imagen digital, excluyendo el análisis referido a su relación con los recursos textuales que ofrece la red social.

El análisis se basa en una investigación cuantitativa centrada en el estudio de caso de la campaña electoral de las elecciones generales de España de 28 de abril de 2019 (28A). La muestra seleccionada incluye un total de 10 perfiles correspondientes a las cuentas oficiales de los cinco principales partidos españoles que se postulaban a la presidencia del Gobierno, en función de su número de votos, y de sus respectivos líderes. Mediante unas categorías de análisis determinadas se estudian parámetros propios de cada componente del binomio texto-imagen, así como su interrelación en el contexto de la red social Instagram. En este sentido, cabe resaltar que, gracias al modelo de análisis diseñado, que ha tenido muy en cuenta la metodología planteada por estudios anteriores, se pretende garantizar la fiabilidad de los resultados.

El principal objetivo de este análisis es determinar qué tipo de relación existe en el uso de la imagen fotográfica y el texto en las cuentas oficiales de Instagram de los actores políticos durante la campaña electoral del 28A. En concreto, el presente estudio se organiza a partir de los siguientes objetivos específicos:

01. Identificar los principales temas de la imagen fotográfica y al texto de Instagram.

O2. Determinar las funciones mayoritarias que cumplen la imagen fotográfica y el texto de Instagram.

O3. Identificar qué partido y/o líder utiliza de forma más efectiva la singularidad icónico-verbal que caracteriza a Instagram.

Este conocimiento aporta una nueva perspectiva al estudio del uso político de Instagram como herramienta estratégica. Consideramos que este aspecto resulta clave para entender la importancia otorgada a cada uno de los parámetros que se tienen en cuenta en la gestión de la comunicación política. La potencia comunicadora de la imagen digital resulta evidente en una plataforma como Instagram que en su origen fue un simple canal de intercambio fotográfico entre aficionados. Sin embargo, en su uso como canal de comunicación política, según López-Rabadán y Doménech-Fabregat (2018), Instagram se encuentra todavía en una fase de experimentación en busca de sus funciones más eficaces y un estilo comunicativo definido.

En ese sentido, se advierte cierta focalización del uso político de la red social en los recursos gráficos, en detrimento de sus recursos textuales. Tal y como sucede en el fotoperiodismo tradicional (Doménech-Fabregat, 2012), la información derivada de los elementos textuales que acompañan a la imagen se convierte en un recurso esencial para su adecuada interpretación. Tomando como punto de partida este criterio, desde este estudio se plantea la hipótesis de que la gestión del binomio imagen fotográfica-texto puede convertirse en un factor clave a tener en cuenta en el posicionamiento de Instagram como instrumento de comunicación política en términos de calidad informativa. Además, en esta red social, el uso de recursos textuales como la geolocalización, por ejemplo, pueden contribuir a posicionar las publicaciones y darles mayor difusión (Cartes-Barroso, 2018). Por todo ello, los resultados obtenidos pueden tener una aplicación profesional en la consultoría política y en la gestión de redes sociales dentro del campo de

Instagram permite a los líderes políticos generar un mensaje visual de gran impacto viral que posibilita una interacción natural y cercana con la ciudadanía la comunicación política. 


\section{Contexto científico}

\subsection{Peso de la imagen en la comunicación política digital}

La propuesta que Sartori (1998) defendió acerca de la preponderancia de lo visible sobre lo inteligible en los años noventa del siglo pasado ha adquirido un significado más completo con la evolución tecnológica de la industria mediática. En una cultura como la actual, dominada por lo icónico (Quevedo-Redondo; Portalés-Oliva, 2017), las imágenes se han convertido en el vehículo prioritario de comunicación de la sociedad (Ruiz-del-Olmo; Bustos-Díaz, 2016), y los actores políticos la han incorporado progresivamente a sus estrategias de comunicación, llegando incluso a ocupar un papel central en el discurso político y mediático (Ardèvol; Muntañola, 2004) en busca de atraer a nuevos seguidores.

El poder político ha necesitado desde siempre proyectar y controlar su imagen (López-Rabadán; López-Meri; Doménech-Fabregat, 2016) y, en la actualidad, gracias a la utilización de las tecnologías digitales, han encontrado en las redes sociales un espacio óptimo dada su capacidad para aportar nuevos significados y narrativas a las instantáneas (Orihuela, 2011; Soulages; San-Ginés-Aguilar, 2012). La distribución fotográfica se ha convertido en una parte fundamental de la comunicación política digital, si bien, según apuntan López-Rabadán, López-Meri y Doménech-Fabregat,

"Ios conceptos tradicionales de autoría, propiedad, privacidad y autenticidad han perdido su sentido convencional" (López-Rabadán; López-Meri; Doménech-Fabregat, 2016, p. 169).

Además, la diversidad de imágenes que se incluyen hoy en día en el fotoperiodismo presenta una variedad heterogénea de tipos y fines. Quizás esta característica explique porqué las fotografías se alejan en muchas ocasiones de los fundamentos informativos (Fontcuberta, 1997).

El protagonismo de la imagen ha sido tal que ha tomado más relevancia que el propio texto, y su uso político en redes sociales con fines estratégicos ha crecido significativamente. De hecho, varias de las transformaciones de la representación de la política en los medios se han identificado como consecuencia de la importancia de la imagen (Oliva; Pérez-Latorre; Besalú, 2015), entre otros factores. Y es que la imagen aumenta la capacidad del receptor para resolver su mensaje en una idea simplificada, factor que aumenta su potencial comunicativo. Así, los actores políticos la utilizan como una vía para acercarse al público y construir una imagen amable de cara a su comunidad de seguidores (López-Meri, 2016).

Especialmente en la comunicación política, la imagen no representa la realidad sino que tiene una marcada gestión estratégica -ya sea por acción u omisión- de lo que los equipos de comunicación quieren transmitir a la ciudadanía (Viounnikoff-Benet, 2017). El uso político de la narrativa visual hace que se trate de producir en la mente del electorado un resultado favorable para quien difunde la operación (Muñoz-Alonso, 1989), por lo que la proyección de una buena imagen política, según Viounnikoff-Benet,

"no es la que refleja la realidad sino la que logra una visión favorable, aunque esté muy alejada de esa realidad" (Viounnikoff-Benet, 2017, p. 62).

El uso político de la imagen se intensifica conforme se acerca la convocatoria electoral, si bien son los partidos emergentes los que hacen un uso más regular de esta (López-Rabadán; López-Meri; Doménech-Fabregat, 2016). Efectivamente, la imagen visual es el mensaje, de forma que esta juega un rol crucial en la construcción de imágenes políticas por lo que su apariencia debe ser estudiada milimétricamente y trabajada de forma impoluta por los gabinetes de comunicación (Schill, 2012). Con este pretexto, la potencia comunicadora de la imagen digital resulta evidente en una red social como Instagram que surgió como un canal de intercambio fotográfico.

\subsubsection{Uso político de la imagen en Instagram}

Si tradicionalmente las imágenes han constituido un recurso estratégico en la gestión de la comunicación política dada su influencia en la forma que la ciudadanía interpreta sus mensajes (Schill, 2012), la aparición de Instagram ha construido una cultura visual de la política en la que, según López-Rabadán y Doménech-Fabregat,

"se mezclan lo informativo y lo personal, lo ideológico y el entretenimiento con un estilo potencialmente espectacular" (López-Rabadán; Doménech-Fabregat, 2018, p. 1014).

La política ha encontrado en Instagram un campo ilimitado de expansión de un modelo comunicativo basado en el poder de denotación de las fotografías (Quevedo-Redondo; Portalés-Oliva, 2017).

En esta línea, los políticos están optando por adoptar sus estrategias de comunicación al contexto de la red social con técnicas narrativas derivadas de la mediatización como la visualización, simplificación o polarización (Meyen; Thieroff; Strenger, 2014). Con ello buscan la movilización de sus seguidores y la generación de engagement político, especialmente entre el público más joven. Los representantes del panorama gubernamental contemporáneo comparten instantáneas en Instagram fomentando con ello un fenómeno que enlaza con el de la popularización política (Street, 2016). En consecuencia, el espectáculo invade el terreno informativo y convierte la privacidad de los actores políticos en objeto de las pretensiones de conocimiento por parte de la ciudadanía. Este hecho se ve acentuado más si cabe por lo que algunos expertos denominan "campaña permanente" (Blumenthal, 1980). El electorado es volátil e indeciso, y en este contexto, el infotainment ayuda a los líderes a conectar con los electores menos interesados por los asuntos públicos (Velert, 2020). 
Estudios recientes sobre el uso político de la imagen en Instagram han probado que los partidos políticos apuestan especialmente por el empleo de la fotografía frente al vídeo (Marcos-García; Alonso-Muñoz, 2017). Más allá de la imagen, los políticos hacen un uso bastante frecuente de los recursos gráficos que acompañan a esta, como son los símbolos o las etiquetas (hashtags), aunque no siempre con el mismo ímpetu dado que no todas las formaciones hacen un uso consciente de la efectividad de estos elementos para ayudar a una mejor monitorización y conseguir unos mejores resultados de posicionamiento online.

\subsection{Relación imagen fotográfica-texto en Instagram y su gestión estratégica como vértice de la comunica- ción política}

A pesar de su creciente protagonismo en las dinámicas comunicativas, las imágenes fotográficas no funcionan de manera independiente, sino que se benefician del conocimiento histórico y cultural existente dentro de la audiencia. Para ello, por lo general, operan en conjunción con argumentos lingüísticos o textuales (Schill, 2012), los cuales anclan un sentido concreto para cada imagen. En este sentido, se hace necesaria la presencia del pie de foto que Roland Barthes, uno de los principales representantes del estructuralismo y la semiología de la imagen, definió de la siguiente forma:

"Es un mensaje parásito, destinado a connotar la imagen, es decir, a insuflarle uno o varios significados secundarios. En otras palabras, esto representa un vuelco histórico importante, la imagen ya no ilustra la palabra; es la palabra la que, estructuralmente, es parásita de la imagen" (Fontcuberta, 1990, p. 174).

Tal y como sucede en el fotoperiodismo tradicional, los datos ofrecidos por los elementos textuales que acompañan a la imagen digital se convierten en un recurso esencial para su adecuada interpretación (Doménech-Fabregat, 2012). Esto es, el binomio imagen fotográfica-texto está irremisiblemente condenado a entenderse y a ser gestionado de manera complementaria. Alonso-Erausquin define esta simbiosis de la siguiente forma:

"Hay datos que la imagen llamada analógica -ampliable también para la digital- no puede transmitir, mientras que la palabra - pie de foto- sirve para transmitir cualquier dato o relatar cualquier suceso. Pero la capacidad de fidelidad y concreción que la imagen posee cuando muestra hechos, protagonistas y escenarios, no puede ser alcanzada fácilmente a través de la palabra. [...] Palabra e imagen conviven en un proceso de complementación más o menos afortunado. Ningún medio de información puede cumplir su objetivo únicamente a través de imágenes" (Alonso-Erausquin, 1995, p. 69).

La imagen fotográfica y el texto del pie de foto funcionan a pleno rendimiento cuando se trabajan de forma indisoluble, en tanto que la primera, a nivel informativo, depende del pie de foto que la acompaña para su correcta interpretación (Doménech-Fabregat, 2005). Al respecto, Millás apunta que

“imagen y texto están condenados de por vida a ir de la mano" (Millás, 2005, p. 13).

Ambos se necesitan para adquirir el valor de documento, en tanto que es la imagen la que apela a los sentimientos y es el texto el que realiza un ejercicio racional (Risueño-Sebastián, 2012), dando como resultado una combinación carismática.

En esta línea, Cartier-Bresson (2003) afirma que los pies de foto han de contextualizar verbalmente a la imagen fotográfica y complementarla en los aspectos que no pueden obtenerse a través de la cámara. Según la estudiosa de la imagen Krauss (2002), en su perspectiva benjaminiana del pie de foto, la imagen fotográfica necesita este recurso para dar una señal textual a su significado ya que, de lo contrario, esta carece por sí misma de un código que pueda ser descodificado. Doménech-Fabregat apunta el error de muchos mediadores de las imágenes

"que piensan que las fotos hablan por sí mismas, cuando se ha reflexionado que es todo lo contrario ya que cualquier instantánea espera su explicación o falsificación con un pie” (Doménech-Fabregat, 2005, p. 53).

Aunque en la mayoría de los casos la fotografía y su pie caminan mirándose, Alonso-Erausquin (1995) señala que existen casos en los que no se da este comportamiento, de forma que se produce una mutua ignorancia entre ambos elementos y quedan en la imagen elementos de inconcreción. Es decir, lo capturado y lo escrito pueden ir juntos (la más recomendable) o no encontrarse en ningún punto (Risueño-Sebastián, 2012). A tal efecto, conviene atender a la clasificación de Alonso-Erausquin (1995) sobre los distintos modos fundamentales de interrelación entre el texto e imagen: independencia, redundancia, complementariedad y contradicción:

- independencia: los dos elementos no guardan relación entre sí y, por tanto, no dependen el uno del otro;

- redundancia: ambos "dicen" lo mismo, generándose una duplicidad de contenido de forma que sin uno de los dos elementos se entendería el mismo mensaje;

- complementariedad: según Alonso-Erausquin, es la

"opción que aprovecha el pie para incluir datos o valoraciones que completen y potencien el mensaje en una eficaz interacción con la propuesta visual", es decir, "una simbiosis del dúo verbo-icónico de tal manera que su unión da como resultado un total superior al de la mera suma" (Alonso-Erausquin, 1995, p. 53). 
- contradicción: aunque se da en pocas ocasiones, responde a las situaciones en las que existe oposición entre imagen fotográfica y texto. En este caso, su efecto siempre será negativo, dado que producirá ambigüedad en el receptor y, por tanto, es una falta de rigor periodístico.

En esta línea, dado el creciente carácter visual de la comunicación en el ámbito digital, las fotografías sufren cada vez más manipulaciones o mediaciones, por lo que este fenómeno debería ir acompañado de una mayor preocupación por el pie de foto (Doménech-Fabregat, 2005), tanto en la optimización de su interacción con la imagen fotográfica, como en su adecuada redacción e implicaciones éticas. Además, específicamente en Instagram, el uso de recursos textuales como la geolocalización, por ejemplo, pueden contribuir a posicionar las publicaciones y darles mayor difusión (Cartes-Barroso, 2018), por lo que los equipos de comunicación deben tomar conciencia de la importancia de los recursos textuales en la gestión eficaz de la comunicación política en esta red social.

\section{Metodología}

El diseño metodológico de esta investigación consta de una aproximación de naturaleza cuantitativa basada en el análisis de contenido (Igartua, 2006). En el análisis cuantitativo lo que sirve de información

"es la frecuencia de aparición de ciertas características de contenido" (Bardin, 1996, p. 32),

para lo que es requisito la "reproductividad" de todo instrumento de investigación científica, es decir, que las reglas que lo gobiernen sean explícitas y aplicables a todas las unidades de análisis (Krippendorff, 2004). La aplicación de esta técnica cuantitativa a la presente investigación va a permitir una revisión exhaustiva de las principales características de uso del binomio imagen fotográfica-texto en Instagram en su utilización como vía de comunicación política, tomando como unidad de registro cada publicación en esta red social.

Los criterios de selección de esta red social para su análisis frente a otras como Facebook o Twitter responden, entre otros, al hueco manifiesto de estudios teórico-metodológicos sobre esta y a su creciente penetración en la comunicación política (Selva-Ruiz; Caro-Castaño, 2017). Cabe señalar la complejidad que supone cuantificar este tipo de sucesos, si bien, como en toda investigación científica, se tienen en cuenta la pertinencia y la consistencia deductiva como premisas básicas de aprendizaje.

Con el objetivo de realizar un análisis completo y detallado del fenómeno estudiado se ha utilizado un modelo de categorización construido ad hoc para la presente investigación. Para el diseño de las categorías se han tenido en cuenta estudios precedentes que examinan la utilización de la imagen política en redes sociales (Goodnow, 2013; López-Rabadán; López-Meri; Doménech-Fabregat, 2016), y trabajos específicos sobre el uso de Instagram (Marcos-García; Alonso-Muñoz, 2017; Quevedo-Redondo; Portalés-Oliva, 2017; Selva-Ruiz; Caro-Castaño, 2017, Lalancette; Raynauld, 2017; López-Rabadán; Doménech-Fabregat, 2018), así como análisis centrados en el estudio de las relaciones verbo-icónicas en el ámbito periodístico (Alonso-Erausquin, 1995). El protocolo de análisis está estructurado en dos bloques o niveles de estudio y plantea un total de tres categorías de análisis. Esta propuesta metodológica se muestra en la tabla 1.

Tabla 1. Modelo de análisis

1. Parámetros comunes imagen fotográfica y texto $(5 \mathrm{~W})$

A) Qué. Tema

0. No se identifica

1. Actualidad política

2. Intervención en medios de comunicación

3. Vida privada

4. Otros

B) Cómo. Función

0 . No se identifica

1. Propuesta política

2. Agenda/indicador de presencia

3. Opinión/recomendación

4. Otros

2. Binomio imagen fotográfica-texto

C) Interrelación entre imagen fotográfica y texto (Erausquin, 1995).

0 . No se identifica

1. Independencia: los dos elementos no guardan relación entre ellos y, por tanto, no dependen el uno del otro.

2. Redundancia: los dos elementos "dicen" lo mismo, generándose una duplicidad de contenido de forma que sin uno de los dos elementos se entendería el mismo mensaje.

3. Complementariedad: los dos elementos completan y potencian el mensaje en una eficaz interacción, de forma que su unión da como resultado un total superior al de la mera suma.

4. Contradicción: existe oposición entre el contenido de ambos elementos, produciendo ambigüedad en el receptor y, por tanto, es una falta de rigor periodístico.

Fuente: elaborado a partir de las aportaciones de Goodnow (2013); López-Rabadán, López-Meri y Doménech-Fabregat (2016); Marcos-García y Alonso-Muñoz (2017); Quevedo-Redondo y Portalés-Oliva (2017); Selva-Ruiz y Caro-Castaño (2017); Lalancette y Raynauld (2017); López-Rabadán y Doménech-Fabregat (2018) y Alonso-Erausquin (1995). 
La definición final de la muestra se ha acotado, desde un punto de vista temporal, a los 15 días correspondientes a la campaña electoral de las elecciones generales en España de abril 2019, desde el viernes 12 de abril hasta el viernes 26 de abril, ambos inclusive. El análisis se ha decantado por el estudio de las elecciones españolas de abril y no por las de noviembre de ese mismo año (que serían las que finalmente dieron lugar a un Gobierno) dado que se observó una disminución del nivel de actividad en Instagram por parte de los actores políticos en las segundas. La elección del período electoral se debe a que se trata de un momento que resulta clave en la esfera política al despertar un gran interés social y consumo informativo entre los ciudadanos y, en consecuencia, una mayor preocupación de los partidos por la comunicación estratégica de su acción política.

Cabe apuntar que, aunque se descargaron 443 posts, para el posterior cruce de datos se excluyeron del análisis 129 publicaciones, que incluían exclusivamente contenido en formato vídeo y quedaban fuera de nuestro objeto de estudio. Por tanto, la muestra está integrada por 314 posts (los correspondientes al formato galería e imagen). La metodología diseñada para el presente estudio se adapta específicamente al análisis de la interrelación entre el texto y la imagen fotográfica.

En relación con los actores seleccionados, la muestra incluye los mensajes publicados por los perfiles oficiales de Instagram de los principales partidos españoles y sus respectivos líderes, según la estimación de voto elaborada a partir del promedio de las encuestas del IMOP (Instituto de Investigación Social y Estudios de Mercado), Demoscopia, NC Report, Celeste-tel y Metroscopia (El país, 2019). Concretamente, se han analizado los perfiles de (tabla 2):

- Pedro Sánchez por el PSOE (Partido Socialista Obrero Español);

- Pablo Casado por el PP (Partido Popular);

- Albert Rivera por Ciudadanos;

- Pablo Iglesias por Unidas Podemos;

- Santiago Abascal por Vox.

Tabla 2. Distribución de la muestra por perfiles analizados

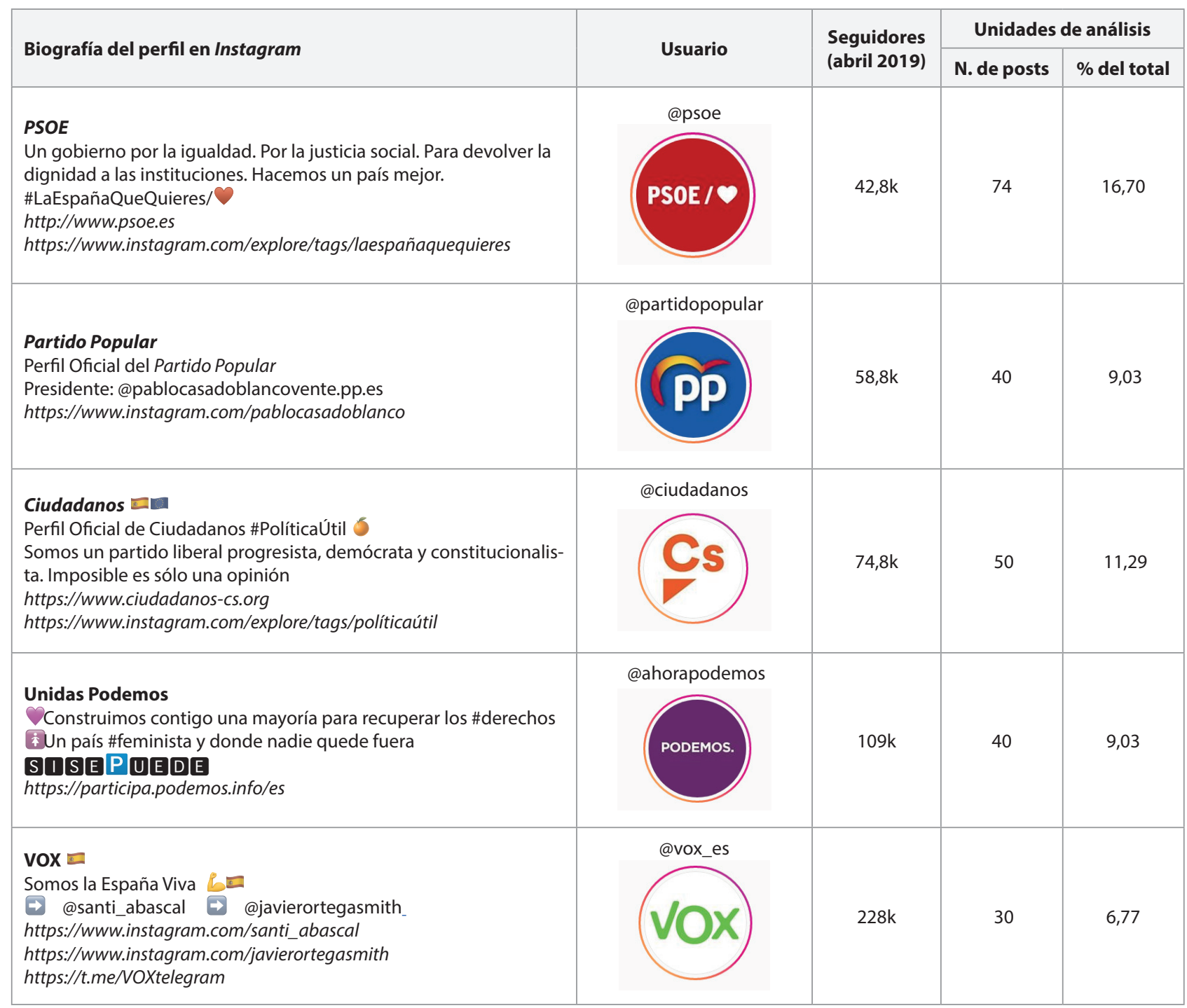




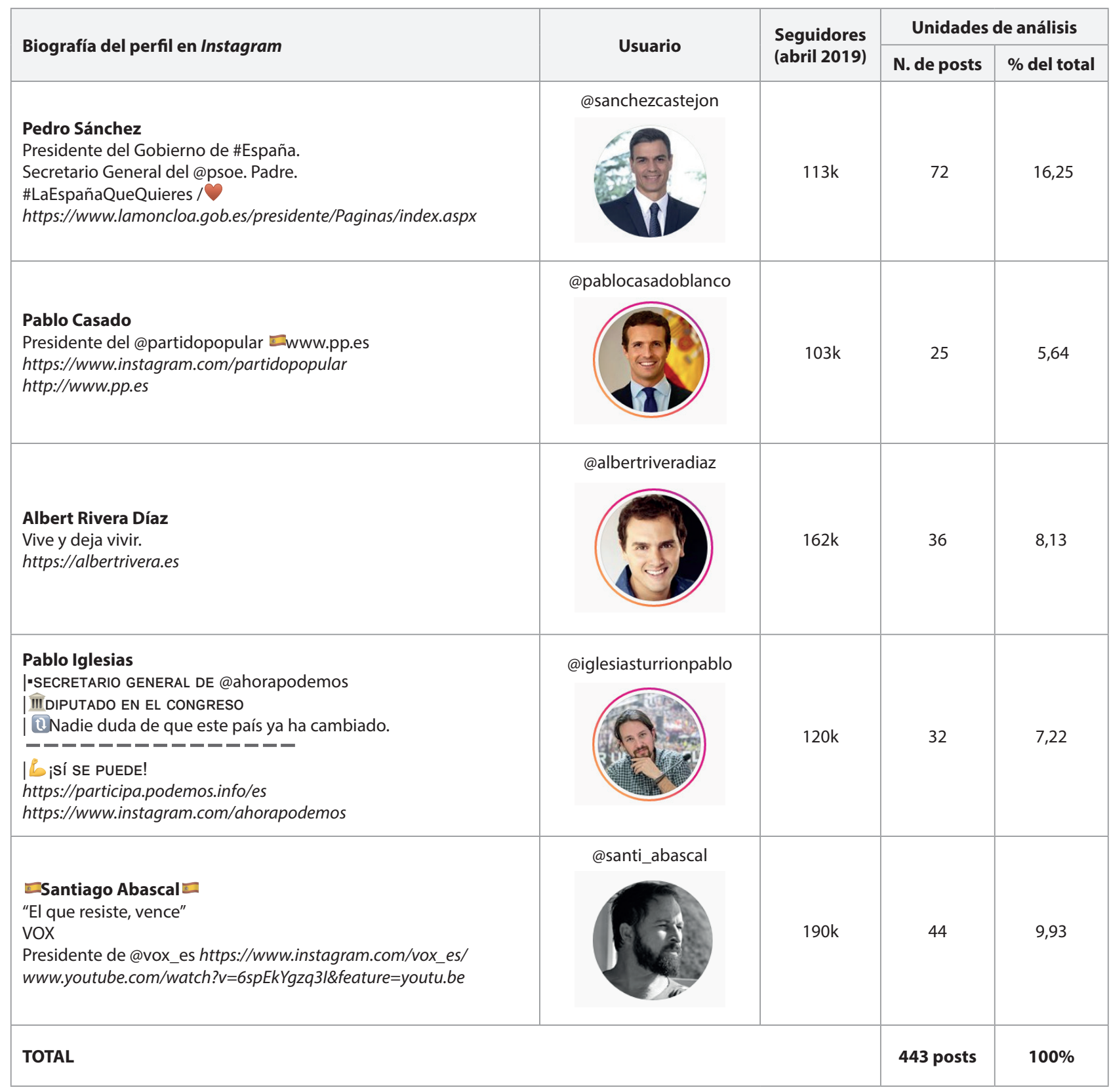

La recogida de la muestra se realizó diariamente durante los 15 días seleccionados (del 12 al 26 de abril de 2019), considerando la vida útil del post desde el momento de su publicación hasta el término del día en cuestión (CEST). Esta premisa pretende mejorar la fiabilidad de la muestra, garantizando así la aleatoriedad de los resultados obtenidos dado que Instagram, como red social, es un ente vivo, por lo que los datos analizados pueden variar tras su estudio. Tras la codificación de la muestra, el tratamiento estadístico de los resultados se ha realizado mediante el programa Microsoft Excel.

\section{Resultados}

Una vez aplicado el modelo metodológico propuesto es posible identificar tendencias significativas con respecto a las categorías de análisis revisadas. Los resultados obtenidos en este estudio confirman un uso regular y normalizado de Instagram por parte de los actores políticos seleccionados. Cabe destacar que los perfiles institucionales son los que publican mayor porcentaje de posts con respecto al total de la muestra: $52,82 \%$ de los partidos frente al $47,18 \%$ de los líderes políticos.

\subsection{Temas de la imagen fotográfica en Instagram}

La temática de la imagen fotográfica en Instagram refiere al asunto o idea al que aluden las referencias visuales de esta. Al respecto, el análisis realizado demuestra que la prioridad de los actores políticos durante el período plebiscitario es habitualmente la de mostrar su actividad profesional en campaña electoral, es decir, en cuestio-
Se detecta un dominio del tipo "Complementariedad", interacción en la que la leyenda se utiliza para incluir información que completa el sentido visual de la fotografía, consiguiendo así un resultado superior al de ambos elementos del binomio por separado 
nes relacionadas con el trabajo diario y la autopromoción de su programa político.

Precisamente, la agenda temática de la imagen fotográfica en Instagram, tanto los perfiles oficiales de los partidos políticos (gráfico 1) como sus líderes (gráfico 2), dan un peso mayoritario al tema "Actualidad política" $(81,25 \%$ y $71,42 \%$ respectivamente) (imagen 1). Esto lo hacen tanto mediante la comuderes). En los temas "Vida privada" (imagen 2) e "Intervención en medios de comunicación" destacan el cos frente al $0,63 \%$ y $5,63 \%$ de los partidos, quienes, al contrario de los candidatos, dan prioridad a otros temas (27,5\%).
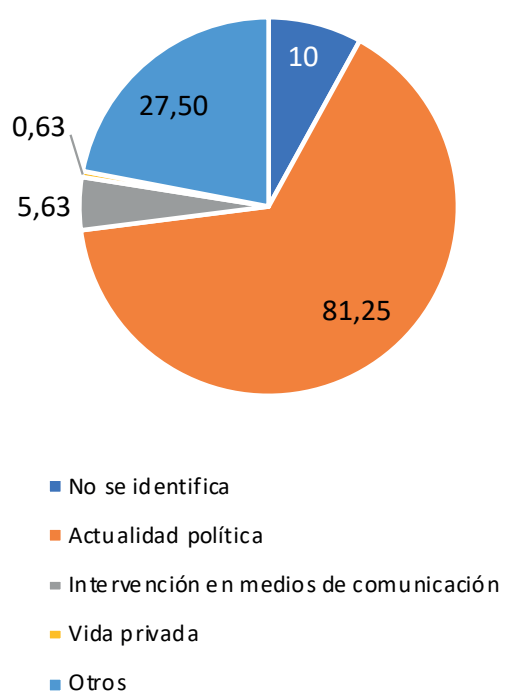

Gráfico 2. Temas de la imagen fotográfica de los líderes políticos en Instagram

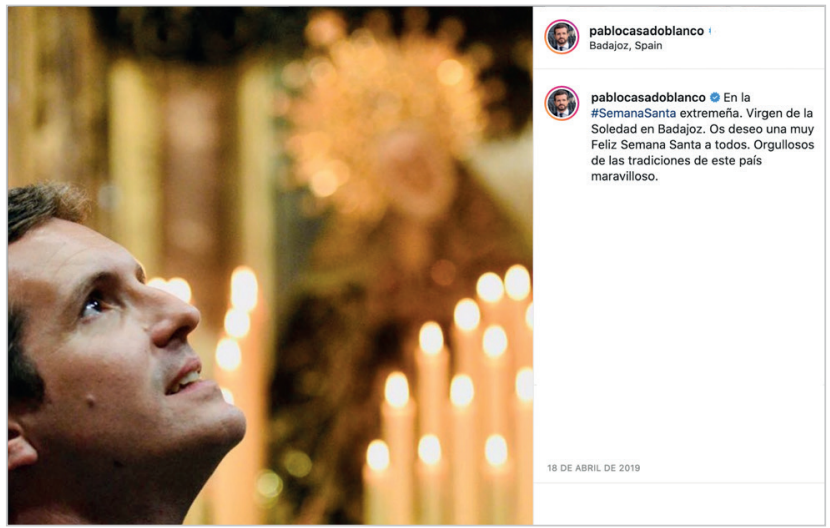

Imagen 2. "Vida privada".

Fuente: perfil de Instagram del líder político Pablo Casado.

\subsection{Temas del texto en Instagram}

Por lo que respecta al tema del texto de las publicaciones de Instagram, este se refiere a la información de la que trata el enunciado en cuestión, es decir, el asunto principal abordado por la proposición.

La "Actualidad política" (imagen 3) copa la mayoría del contenido temático del texto de las publicaciones de Instagram, tanto por parte de los partidos $(90,63 \%)$ (gráfico 3$)$, como de sus respectivos líderes políticos (81,81\%) (gráfico 4). La "Intervención en medios de comunicación" (imagen 4) es el asunto secundario por excelencia del texto, si bien tiene más peso en los perfiles de los candidatos $(10,39 \%)$ con respecto a los de los partidos (7,5\%).

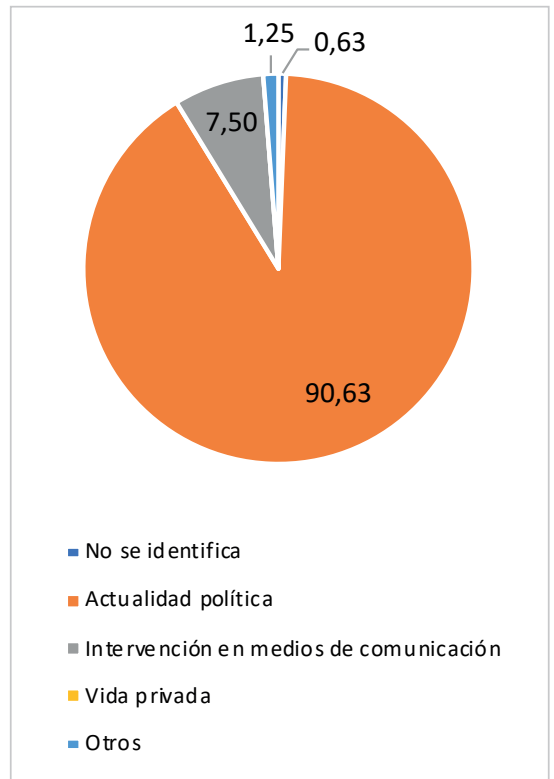

Gráfico 3. Temática del texto de los partidos políticos en Instagram nicación de actos institucionales de partido como de encuentros. El resto de los temas tienen una visibilidad mucho menor en ambos tipos de perfiles analizados (partidos y lí$10 \%$ y el $7,79 \%$ de los líderes políti-

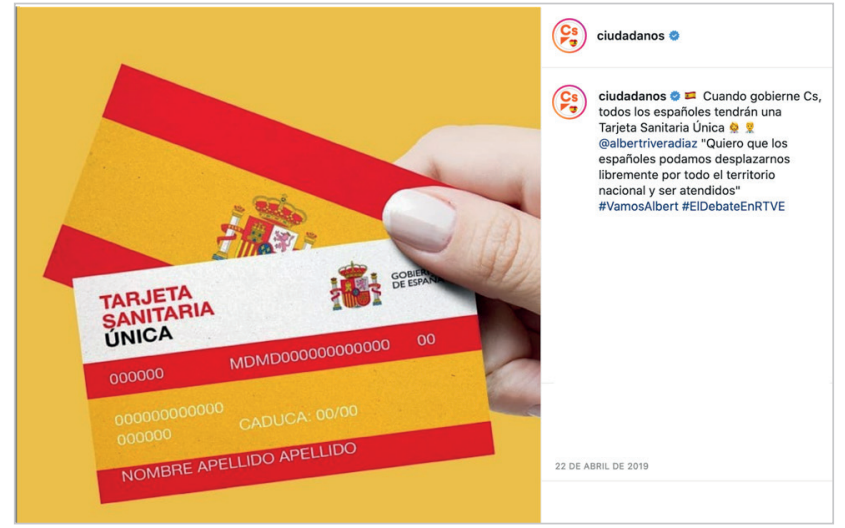

Imagen 1. "Actualidad política".
Fuente: perfil de Instagram del partido político Ciudadanos.

Imagen 1. "Actualidad política".
Fuente: perfil de Instagram del partido político Ciudadanos.
Gráfico 1. Temas de la imagen fotográfica de los partidos políticos en Instagram

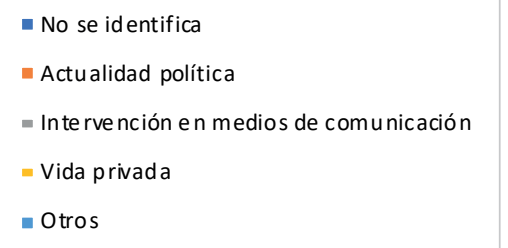

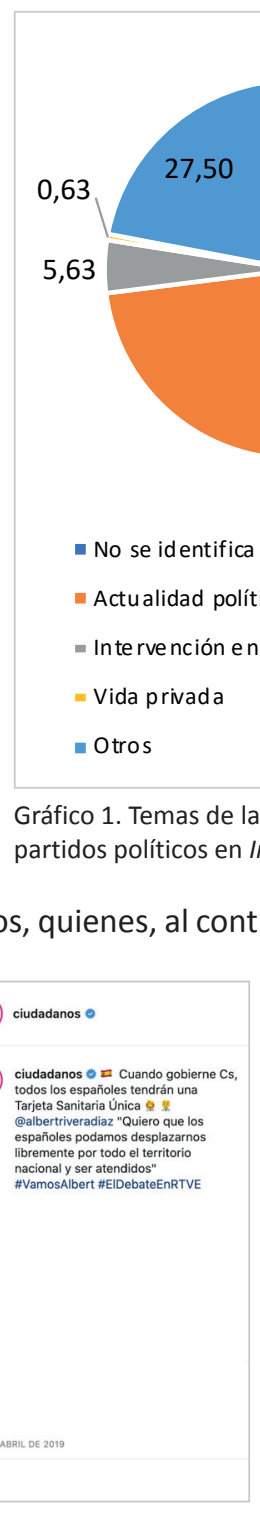

Fuer




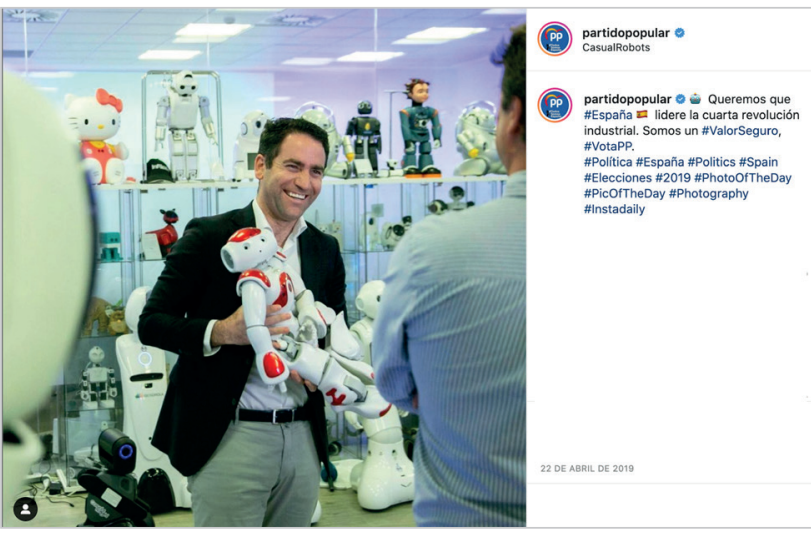

Imagen 3. "Actualidad política".

Fuente: perfil de Instagram del partido político $P P$.

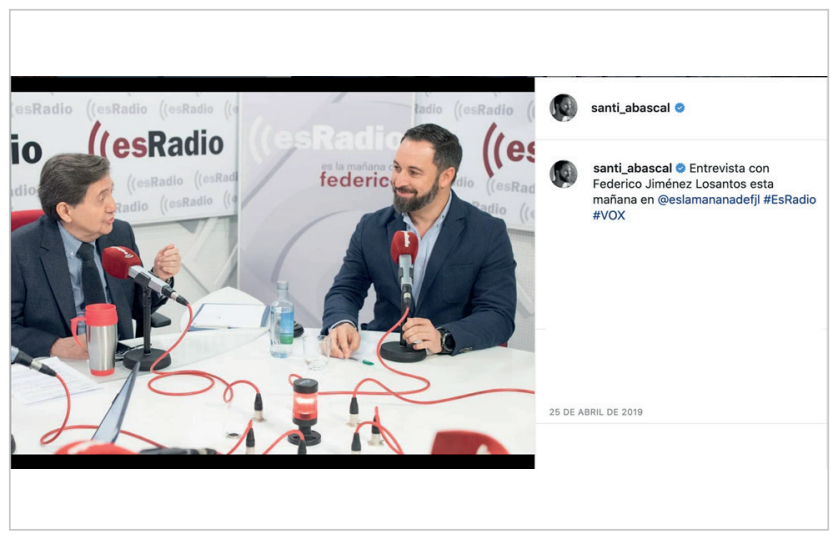

Imagen 4. "Intervención en medios de comunicación". Fuente: perfil de Instagram del líder político Santiago Abascal.

El resto de las cuestiones tienen una presencia bastante limitada como contenido central del texto. En este sentido cabe destacar la mayor personalización del texto en los perfiles de los candidatos con la temática "Vida privada" $(5,84 \%)$ frente a la nula presencia de este aspecto en el texto de los posts de las cuentas oficiales de las formaciones políticas.

Por último, resulta relevante advertir el reducido porcentaje de textos en los cuales no se identifica su temática principal. Bien de forma explícita y/o implícita, un 98\% aproximadamente del total de los textos que acompañan a las publicaciones de Instagram, tanto en las cuentas de los partidos como de los líderes, revelan de forma precisa su temática.

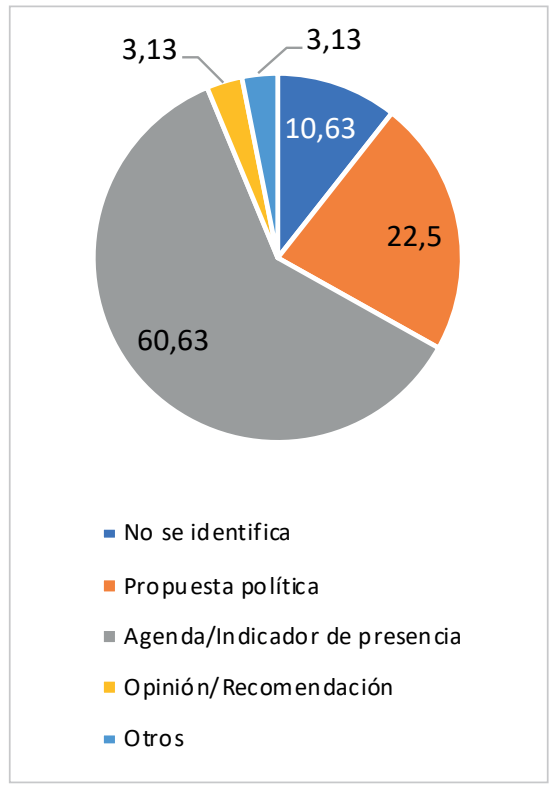

Gráfico 5. Función de la imagen fotográfica de los partidos políticos en Instagram

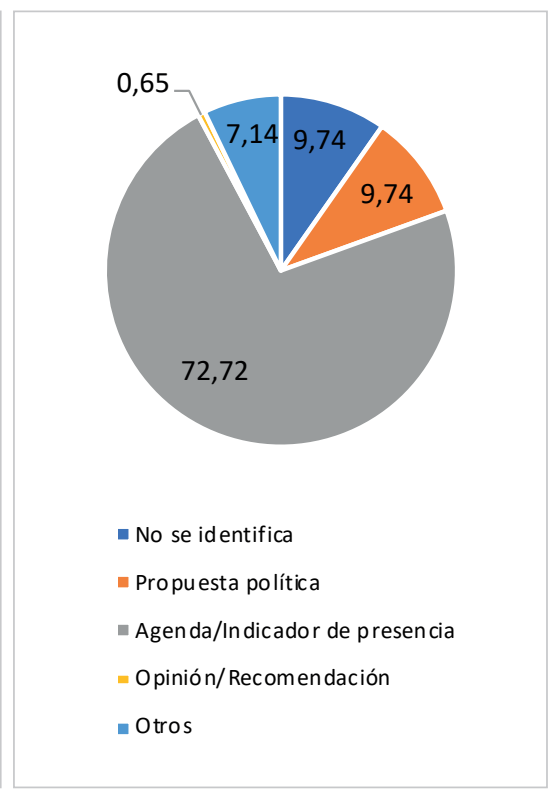

Gráfico 6. Función de la imagen fotográfica de los líderes políticos de Instagram

\subsection{Funciones de la imagen fotográfica en Instagram}

Hacen referencia al papel o propósito, en este caso político, con el que se realiza una publicación en relación con la finalidad que se tiene con respecto al público receptor.

Respecto al uso estratégico de la imagen fotográfica en Instagram (gráficos 5 y 6), se evidencia que los líderes privilegian la función "Agenda/indicador de presencia" (imagen 5) por encima de los partidos (72,72\% y 60,63\% respectivamente). Sin embargo, estos lo hacen con "Propuesta política" (imagen 6) por encima de los líderes (22,5\% de los partidos y 9,74\% de los líderes políticos). Más allá de este uso de la imagen fotográfica, también llama la atención el rol secundario de la función clásica “Opinión/recomendación”, especialmente por parte de los líderes (0,65\%).

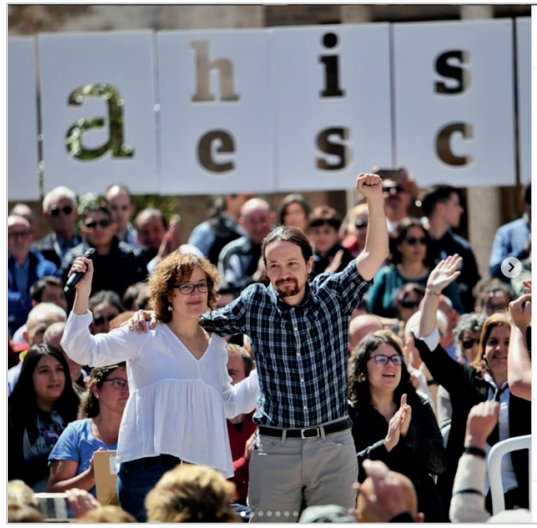

Imagen 5. "Agenda/Indicador de presencia". Fuente: perfil de Instagram del líder político Pablo Iglesias.

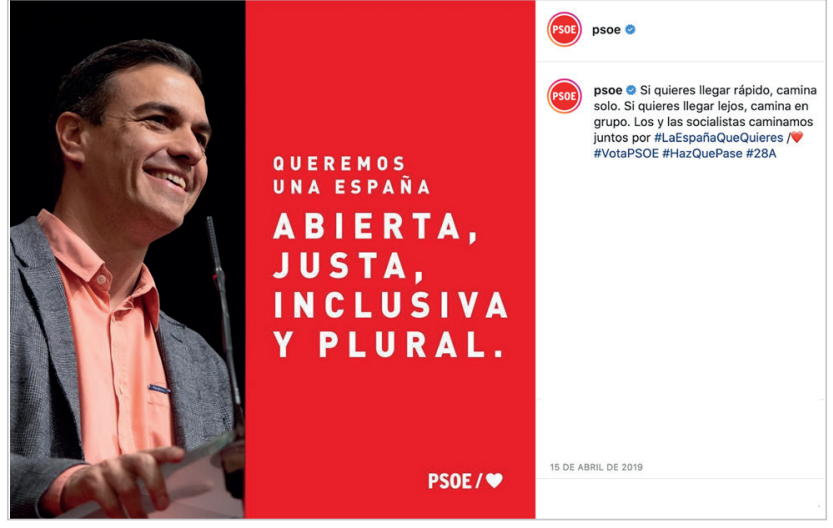

Imagen 6. "Propuesta política".

Fuente: perfil de Instagram del partido político PSOE. 


\subsection{Funciones del texto en Ins- tagram}

La función del texto de las publicaciones en Instagram es el cometido con el que se publica junto a la imagen correspondiente, esto es, la finalidad que se pretende conseguir con cada enunciado.

De acuerdo con las funciones indicadas con anterioridad con respecto al texto de Instagram (gráficos 7 y 8), la tendencia principal es la "Agenda/ indicador de presencia" (imagen 7), si bien son los líderes quienes priorizan el uso de esta función (59,74\%) frente a las cuentas de las formaciones políticas $(43,13 \%)$. Sucede lo contrario con la categoría "Propuesta política" (imagen 8), función con la que los partidos políticos realizan la mitad de sus publicaciones y los candidatos, por su parte, un $32,12 \%$ de estas.

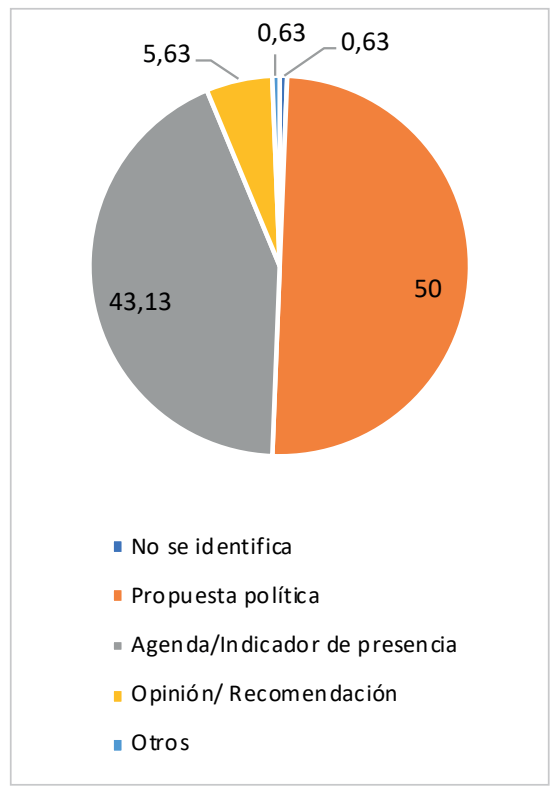

Gráfico 7. Función del texto de los partidos políticos en Instagram

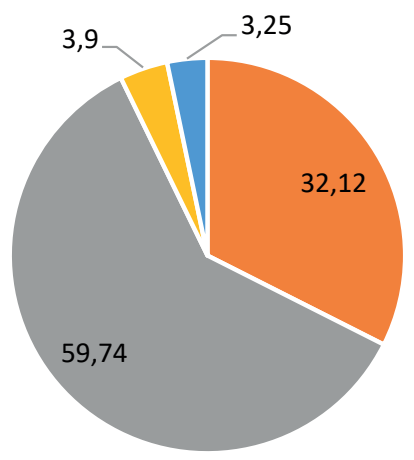

- No se identifica

- Propuesta política

- Agenda/in dicador de presencia

- Opinión/ Recomen dación

Otros

Gráfico 8. Función del texto de los líderes políticos en Instagram

Del resto de funciones analizadas en el texto de Instagram, resulta significativo destacar lo irrelevante de la presencia de la opinión/recomendación en ambos tipos de perfiles estudiados (5,63\% por parte de los partidos políticos y 3,9\% por parte de los líderes).

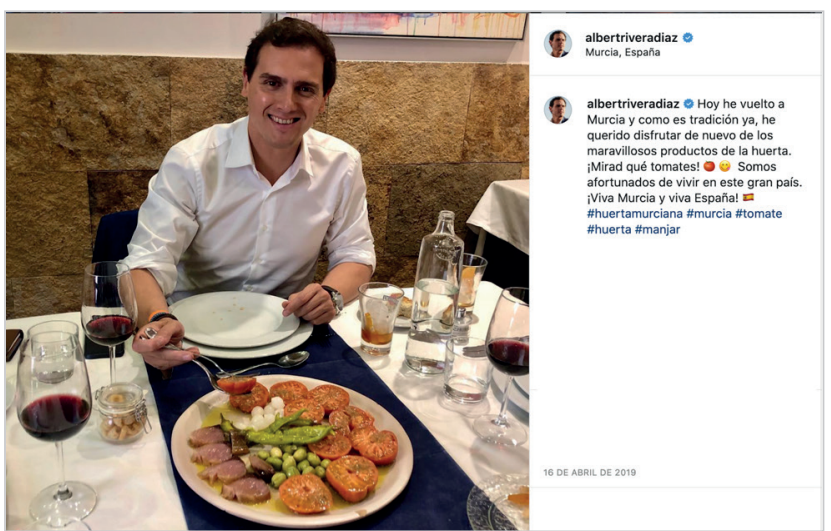

Imagen 7. "Agenda/Indicador de presencia".

Fuente: perfil de Instagram del líder político Albert Rivera.

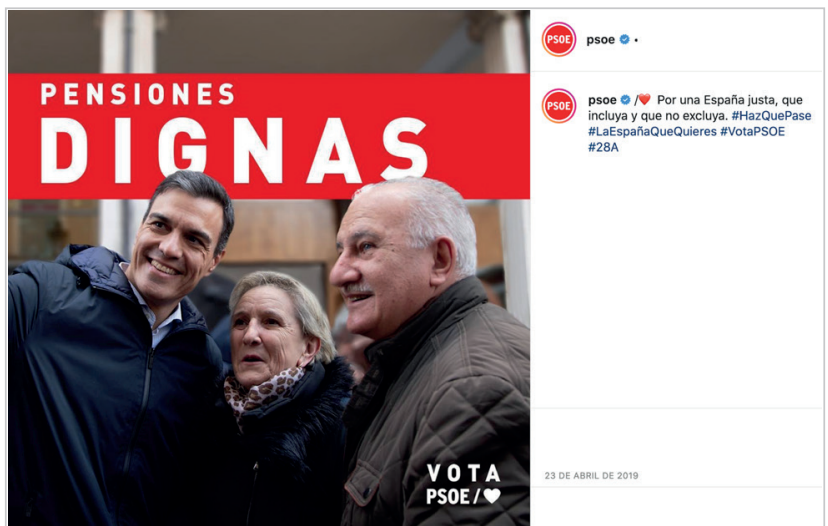

Imagen 8. "Propuesta política".

Fuente: perfil de Instagram del partido político del PSOE.

\subsection{Gestión política de la interrelación entre la imagen fotográfica y el texto en Instagram}

La gestión estratégica de la interrelación entre el binomio imagen fotográfica-texto a nivel político en Instagram hace referencia al tipo de interacción semántica existente entre la fotografía y los recursos textuales que se publican conjuntamente a esta en la red social.

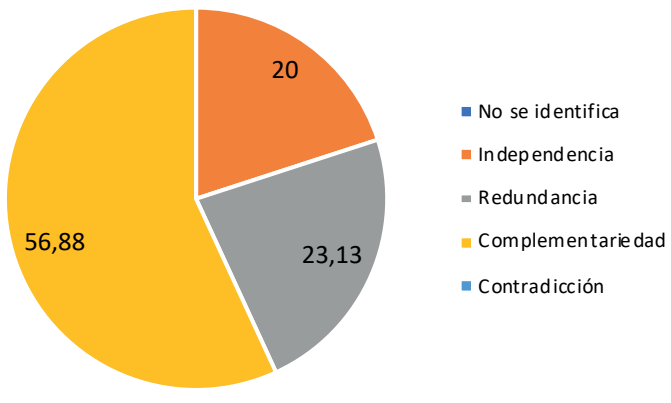

Gráfico 9. Interrelación binomio imagen fotográfica - texto de los partidos políticos en Instagram

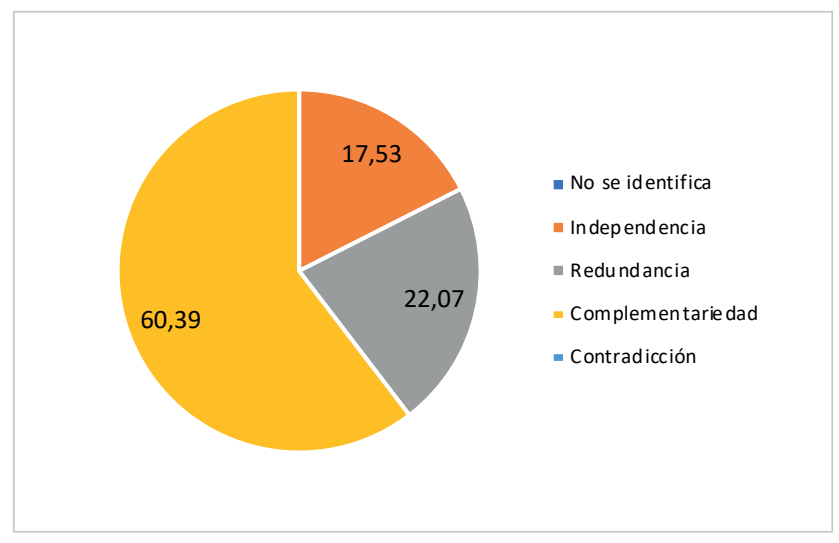

Gráfico 10. Interrelación binomio imagen fotográfica - texto de los líderes políticos en Instagram 
Respecto al tipo de relación existente entre los recursos visuales y textuales en las publicaciones de Instagram (gráficos 9 y 10), se detecta un dominio del tipo "Complementariedad", con cifras muy similares por parte de los partidos políticos $(56,88 \%)$ y sus respectivos líderes (60,39\%). Este tipo de interrelación es el resultado de una correcta planificación de las publicaciones en la plataforma que, tal y como apuntan estudios precedentes (Doménech-Fabregat, 2012), resulta necesario a la hora de interpretar correctamente las apelaciones. De esta forma, el texto o leyenda se utiliza para incluir información que completa el sentido visual de la fotografía, consiguiendo así un resultado superior al de ambos elementos del binomio por separado. Sin duda, es una de las pruebas, entre otros muchos aspectos, de la profesionalización de la gestión estratégica en el uso político de Instagram.

Sin embargo, la presencia significativa de tipos de interacción problemáticos como la "Redundancia" (23,13\% por parte de los partidos y $22,07 \%$ por parte de los candidatos) y la "Independencia" (20\% de las formaciones políticas y $17,53 \%$ de los líderes), evidencia un amplio margen de mejora en la gestión del binomio imagen fotográfica-texto en Instagram. Esto se debe a que estas dos variables no aprovechan en todo su potencial las capacidades informativas de los recursos textuales de Instagram. Cabe mencionar al respecto que la variable "Contradicción" destaca por su ausencia en sendos tipos de perfiles.

En relación con el tipo de interacción entre la fotografía y el texto de las diez cuentas analizadas (gráficos 11 y 12), destaca tanto el partido Ciudadanos, como su líder, Albert Rivera, con respecto a la tendencia preferente por la "Complementariedad" de los recursos visuales y los textuales (imagen 9) (75\% y 79,57\% respectivamente). Con respecto a la variable "Redundancia" (imagen 10), es el perfil del PSOE el que más lo utiliza con respecto al total de sus publicaciones (31,66\%) y el candidato por Unidas Podemos, Pablo Iglesias, el que menos (9,09\%).

Finalmente, los resultados alcanzados revelan el mayor uso de la "Independencia" (imagen 11) como el tipo de interrelación entre los componentes del binomio estudiado por parte del líder popular, Pablo Casado (40\%), mientras que el candidato por Vox, Santiago Abascal (5,26\%), es el que menos utiliza este tipo de interacción entre la fotografía y el texto en sus publicaciones.

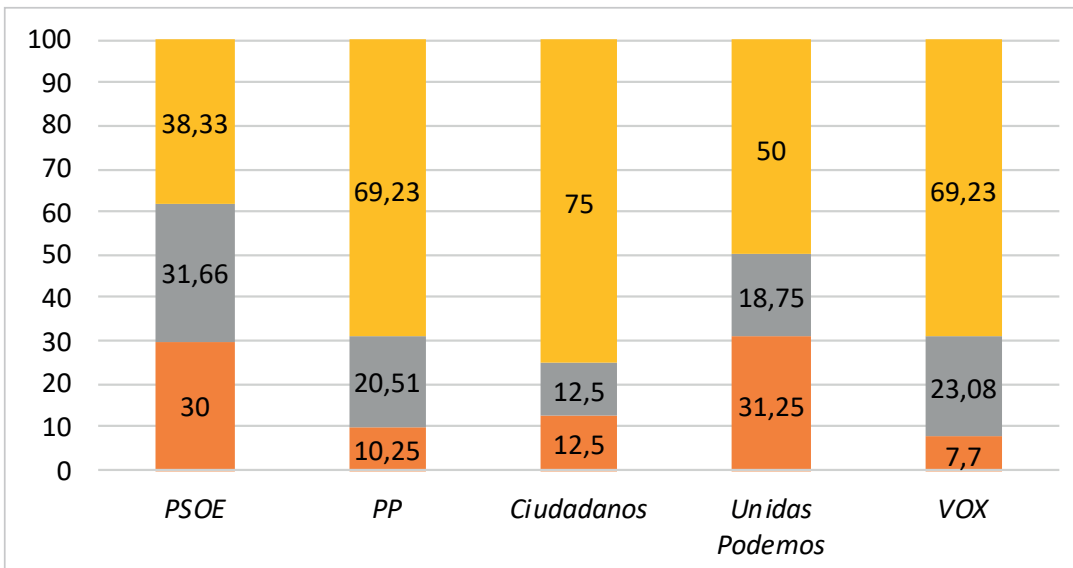

no se identifica Independencia Redundancia Complementariedad Contradicción

Gráfico 11. Interrelación binomio imagen fotográfica-texto de los partidos políticos en Instagram

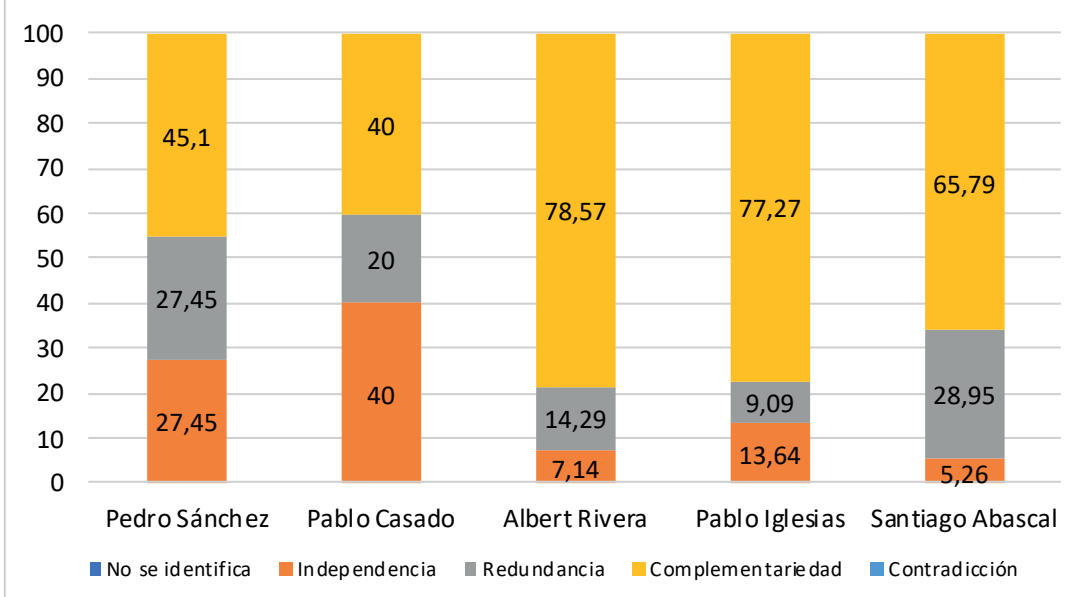

Gráfico 12. Interrelación binomio imagen fotográfica-texto de los partidos políticos en Instagram

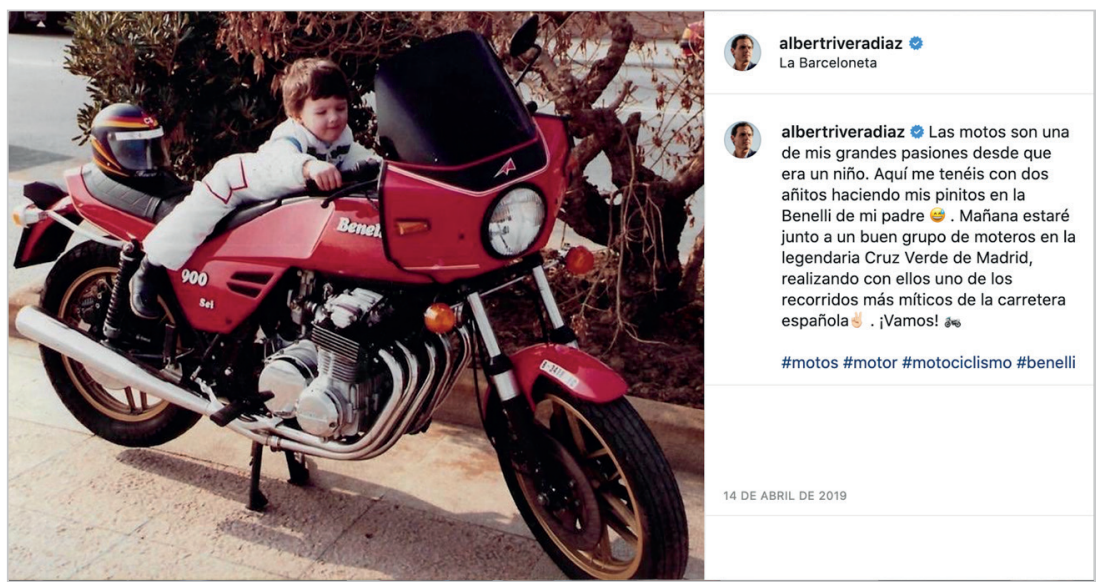

Imagen 9. "Complementariedad".

Fuente: perfil de Instagram del líder político Albert Rivera. 


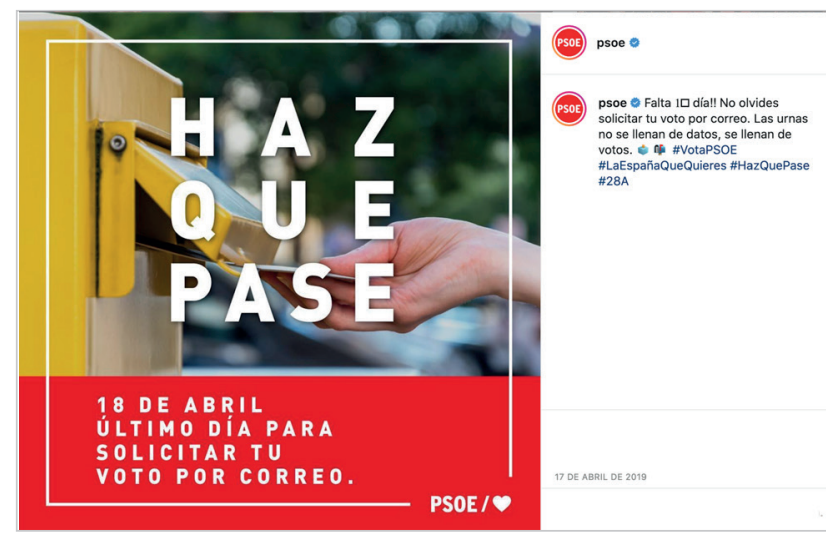

Imagen 10. "Redundancia".

Fuente: perfil de Instagram del partido político PSOE.

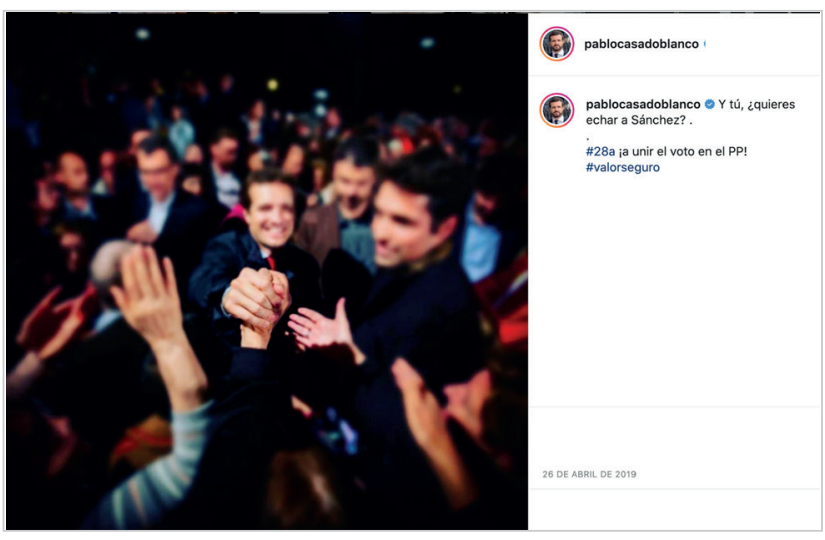

Imagen 11. "Independencia".

Fuente: perfil de Instagram del líder político Pablo Casado.

\section{Conclusiones}

Los resultados obtenidos permiten un diagnóstico completo sobre el tipo de gestión estratégica de la interacción imagen fotográfica-texto en Instagram por parte de los partidos políticos españoles y sus respectivos líderes. Globalmente y de acuerdo con lo que apuntan estudios precedentes (López-Rabadán; Doménech-Fabregat, 2018), se constata parcialmente que el uso estratégico de Instagram como herramienta de comunicación política todavía se encuentra en fase experimental, si bien resulta significativo como, aunque con mucho camino por recorrer, comienza a esbozar un estilo comunicativo propio.

Aunque el uso político de Instagram se encuentra en un proceso de normalización avanzado, aún se requiere una mayor profesionalización comunicativa de la plataforma que consolide un patrón definido en aspectos como, por ejemplo, la gestión estratégica del binomio fotografía-texto. Dentro del caso de la campaña electoral del 28A, el PSOE por parte de los partidos, y Pablo Casado y Pedro Sánchez por parte de los líderes son buenos ejemplos de falta de aprovechamiento del potencial de la interacción entre la imagen fotográfica y los recursos textuales de la plataforma Instagram. Pero, al mismo tiempo, también se detecta en muchos casos un uso planificado y gestionado estratégicamente para sacar el máximo rendimiento al binomio fotografía-texto, como demuestran los casos de Ciudadanos, el Partido Popular, Vox, Albert Rivera y Pablo Iglesias.

Los resultados obtenidos sobre los parámetros analizados permiten identificar una serie de tendencias que pueden resultar aplicables más allá del caso español. Al respecto, se determina que la variable "Actualidad política" tiene mayor relevancia como temática principal de la fotografía y el texto de forma independiente, tanto por parte de los partidos políticos como de los candidatos, quienes utilizan mayoritariamente los dos componentes del binomio estudiado en las publicaciones de Instagram para realizar un seguimiento político del período electoral.

En cuanto a la función de la fotografía y los recursos textuales, también se identifica que la comunicación de la "Agenda/ indicador de presencia" es la finalidad principal de la imagen fotográfica. Esta tendencia también se cumple con el texto de Instagram, refutando así la idea que su función principal sea la "Propuesta política". Este hecho puede deberse a:

- el elevado ritmo de actividad política que caracteriza a los períodos electorales;

- la exigencia profesional de la comunicación política digital de trasladar la presencia física de los líderes en distintos actos institucionales, factor que favorece su cercanía a la ciudadanía.

En esta línea, que el tema "Actualidad política" y la función "Agenda/indicador de presencia" sean dominantes en la gestión política de Instagram es algo que concuerda con lo que trabajos centrados en el empleo que partidos y candidatos hacen de Twitter en campaña electoral han demostrado (López-Meri; Marcos-García; Casero-Ripollés, 2017). Sin embargo, a diferencia de lo que ocurría en Twitter, en líneas generales no se detectan diferencias notables en el uso de esta plataforma entre, por una parte, los partidos políticos emergentes frente a los partidos tradicionales y, por otra, entre formaciones políticas y líderes.

Por último, se rechaza la variable "Independencia" como modo de interrelación mayoritario entre la imagen fotográfica y el texto en el uso político de Instagram, dándose el tipo de interacción "Complementariedad" en más de la mitad de las publicaciones totales, tanto de líderes como de partidos. Sin embargo, los resultados obtenidos no evidencian una gestión profesional generalizada de este aspecto dado que aproximadamente en un $40 \%$ de las publicaciones de Instagram estudiadas, una proporción que puede estimarse significativa, no se da una interrelación informativa efectiva entre la imagen fotográfica y los recursos textuales que la acompañan.

Existe una presencia importante de tipos de interacción problemáticos como la "Redundancia" y la "Independencia" que evidencian un amplio margen de mejora en la gestión del binomio imagen fotográfica-texto en Instagram 
Resulta evidente que Instagram ha llegado a la comunicación política de forma decidida, si bien deben tenerse en cuenta diferentes aspectos en su profesionalización como canal de expresión de los actores políticos. En este sentido, el presente trabajo concluye que, en términos generales, no se consigue actualmente un aprovechamiento potencial del tándem icono-verbal en la red social. Esta idea es coherente con la que plantea Doménech-Fabregat (2005) de que la imagen fotográfica y el texto del pie de foto funcionan a pleno rendimiento cuando se trabajan de forma indisoluble. Sin embargo, existe un elevado porcentaje de posts que, por su independencia o redundancia, dejan en la imagen elementos de inconcreción (Alonso-Erausquin, 1995) y queda, por ende, un espacio ambiguo para interpretaciones erróneas.

Conforme a lo expuesto por Krauss (2002), sólo un 55\% aproximadamente de las imágenes fotográficas de los actores políticos del panorama actual podrían ser descodificadas gracias la contextualización complementaria de los recursos verbales que la acompañan. En esta línea, con relación a la postura de Risueño-Sebastián (2012) de que es la imagen la que apela a los sentimientos y el texto el que realiza un ejercicio racional y que, a su vez, son ambos los que se necesitan mutuamente para adquirir el valor de documento, el presente estudio prueba que, según esta afirmación, casi la mitad de las publicaciones de los actores políticos en Instagram no cumplen estos criterios de validez.

La principal limitación de este trabajo es la complejidad de medir un fenómeno de estas características dada la diversidad de formatos comunicativos que acoge la red social Instagram. De igual forma, aunque los resultados obtenidos pueden ser extrapolados a otros casos similares, la muestra temporal analizada responde a un período político con unas características muy concretas, por lo que cabría comprobar si estos siguen la misma tendencia durante la actividad política ordinaria. Dichas limitaciones abren la puerta a profundizar en el análisis estratégico de la interrelación de la imagen fotográfica y el texto con otra muestra de diferentes características, bien en el criterio temporal o bien en el de selección de los actores políticos, con el objetivo de comparar sus resultados y extraer conclusiones representativas al respecto.

\section{Referencias}

Alonso-Erausquin, Manuel-Alonso (1995). Fotoperiodismo: formas y códigos. Síntesis. ISBN: 8477382816

Annunziata, Rocío; Ariza, Andrea-Fernanda; March, Valeria-Romina (2018). “'Gobernar es estar cerca'. Las estrategias de proximidad en el uso de las redes sociales de Mauricio Macri y María Eugenia Vidal". Revista mexicana de opinión pública, n. 24, pp. 71-93.

https://doi.org/10.22201/fcpys.24484911e.2018.24.61520

Ardèvol, Elisenda; Muntañola, Nora (coords.) (2004). Representación y cultura audiovisual en la sociedad contemporánea. Barcelona: Universitat Oberta de Catalunya. ISBN: 8497880153

Bardin, Laurence (1996). Análisis de contenido. Madrid: Akal Ediciones. ISBN: 9788476000939

Blumenthal, Sidney (1980). The permanent campaign. Inside the world of elite political operatives. Boston, Beacon Press. ISBN: 9780807032084

Burson-Marsteller (2018). "World leaders on Instagram, 2017". Twiplomacy, April 12.

http://twiplomacy.com/blog/world-leaders-instagram-2017

Cartes-Barroso, Manuel-Jesús (2018). “El uso de Instagram por los partidos políticos catalanes durante el referéndum del 1-O". Revista de comunicación de la Seeci, n. 47, pp. 17-36.

https://doi.org/10.15198/seeci.2018.0.17-36

Cartier-Bresson, Henri (2003). Fotografiar del natural. Barcelona: Gustavo Gili. ISBN: 8425230561

Doménech-Fabregat, Hugo (2005). La fotografía informativa en la prensa generalista. Del fotoperiodismo clásico a la era digital. Tesis doctoral. Universitat Jaume I. Repositorio institucional.

http://repositori.uji.es/xmlui/handle/10803/10461

Doménech-Fabregat, Hugo (2012). "El pie de foto como unidad informativa en la prensa española: usos y características". Textual and visual media, n. 5, pp. 209-224.

http://textualvisualmedia.com/index.php/txtvmedia/article/view/58/48

El país (2019). "Promedio de encuestas El país". El país, 4 noviembre.

https://elpais.com/especiales/2019/elecciones-generales/encuestas-electorales

Filimonov, Krill; Russmann, Uta; Svensson, Jakob (2016). "Picturing the party: Instagram and party campaigning in the 2014 Swedish elections". Social media + society, v. 2, n. 3.

https://doi.org/10.1177/2056305116662179

Fontcuberta, Joan (1990). Fotografía: conceptos y procedimientos: una propuesta metodológica. Barcelona: Gustavo Gili. ISBN: 8425214084 
Fontcuberta, Joan (1997). El beso de Judas. Fotografía y verdad. Barcelona: Gustavo Gili. ISBN: 9788425228322

Goodnow, Trischa (2013). "Facing off: A comparative analysis of Obama and Romney Facebook timeline photographs". American behavioral scientist, v. 57, n. 11, pp. 1584-1595.

https://doi.org/10.1177/0002764213489013

Igartua, Juan-José (2006). Métodos cuantitativos de investigación en comunicación. Barcelona: Bosch. ISBN: 97884 97902717

Krauss, Rosalind (2002). Lo fotográfico: por una teoría de los desplazamientos. Barcelona: Gustavo Gili. ISBN: 84252 18918

Krippendorff, Klaus (2004). Content analysys: An introduction to its methodology, $2^{\text {nd }}$ ed. Thousand Oaks, CA: Sage. ISBN: 9780761915447

Lalancette, Mireille; Raynauld, Vincent (2019). "The power of political image: Justin Trudeau, Instagram, and celebrity politics". American behavioral scientist, v. 63, n. 7, pp. 888-924.

https://doi.org/10.1177/0002764217744838

López-García, Guillermo (2017). “Comunicación política y discursos sobre el poder". El profesional de la información, v. 26, n. 4, pp. 573-578.

https://doi.org/10.3145/epi.2017.jul.01

López-Meri, Amparo (2016). "Periodismo en Twitter. La contribución de los usuarios al flujo informativo". Cuadernos. info, n. 39, pp. 241-257.

https://doi.org/10.7764/cdi.39.825

López-Meri, Amparo; Marcos-García, Silvia; Casero-Ripollés, Andreu (2017). "What do politicians do on Twitter? Functions and communication strategies in the Spanish electoral campaign of 2016". El profesional de la información, v. 26, n. 5, pp. 795-804.

https://doi.org/10.3145/epi.2017.sep.02

López-Rabadán, Pablo; Doménech-Fabregat, Hugo (2018). "Instagram y la espectacularización de las crisis políticas. Las 5W de la imagen digital en el proceso independentista de Cataluña”. El profesional de la información, v. 27, n. 5, pp. 1013-1029.

https://doi.org/10.3145/epi.2018.sep.06

López-Rabadán, Pablo; López-Meri, Amparo; Doménech-Fabregat, Hugo (2016). "La imagen política en Twitter. Usos y estrategias de los partidos políticos españoles". Index. Comunicación, v. 6, n. 1, pp. 165-195.

http://hdl.handle.net/10234/165146

Marcos-García, Silvia; Alonso-Muñoz, Laura (2017). "La gestión de la imagen en campaña electoral. El uso de Instagram por parte de los partidos y líderes españoles en el 26J". En: Sierra-Sánchez, Javier; Liberal-Ormaechea, Sheila (eds.). Uso y aplicación de las redes sociales en el mundo audiovisual y publicitario. McGraw-Hill, pp. 107-118. ISBN: 9788448613570

Meyen, Michael; Thieroff, Markus; Strenger, Steffi (2014). “Mass media logic and the mediatization of politics: a theoretical framework". Journalism studies, v. 15, n. 3, pp. 271- 288.

https://doi.org/10.1080/1461670X.2014.889459

Millás, Juan-José (2005). Todo son preguntas. Península. ISBN: 8483076578

Montagut, Marta; Carrillo, Nereida (2017). “Estrategias de espectacularización en las tertulias políticas televisivas. Caso de la cobertura de las elecciones municipales de Barcelona de 2015". El profesional de la información, v. 26, n. 4, pp. 621-629. https://doi.org/10.3145/epi.2017.jul.06

Muñoz-Alonso, Alejandro (1989). Política y nueva comunicación: el impacto de los medios de comunicación de masas en la vida política. Madrid: Fundesco. ISBN: 8486094461

NewsWhip (2016). "Election 2016: How are the candidates using Instagram?". NewsWhip, January 26. https://www.newswhip.com/2016/01/election-2016-how-are-the-candidates-using-instagram

Oliva, Mercè; Pérez-Latorre, Óliver; Besalú, Reinald (2015). “Celebrificación del candidato. Cultura de la fama, marketing electoral y construcción de la imagen pública del político". Arbor, v. 191, n. 775.

https://doi.org/10.3989/arbor.2015.775n5009

Orihuela, José-Luis (2011). Mundo Twitter: una guía para comprender y dominar la plataforma que cambió la Red. Barcelona: Alienta. ISBN: 9788492414895

Parmelee, John H.; Roman, Nataliya (2019). "Insta-politicos: Motivations for following political leaders on Instagram". Social media+ society, v. 5, n. 2.

https://doi.org/10.1177/2056305119837662 
Pellisser-Rossell, Nel.lo; Pineda, Antonio (2014). “Información política televisiva y espectacularización: un análisis comparativo de programas informativos y de infoentretenimiento". Estudios sobre el mensaje periodístico, v. 20, n. 2, pp. $821-839$. http://hdl.handle.net/11441/61334

Pérez-Curiel, Concha; García-Gordillo, Mar (2020). “Del debate electoral en TV al ciberdebate en Twitter. Encuadres de influencia en las elecciones generales en España (28A)". Profesional de la información, v. 29, n. 4.

https://doi.org/10.3145/epi.2020.jul.05

Quevedo-Redondo, Raquel; Portalés-Oliva, Marta (2017). “Imagen y comunicación política en Instagram. Celebrificación de los candidatos a la presidencia del Gobierno". El profesional de la información, v. 26, n. 5, pp. $916-927$.

https://doi.org/10.3145/epi.2017.sep.13

Relaño, Alberto (2016). "El uso de Instagram y Snapchat en España se dispara". Kantar.

Risueño-Sebastián, Raúl (2012). La imagen periodística como protagonista en el periódico El País. Tesis de maestría. Universitat Politècnica de València.

http://hdl.handle.net/10251/16672

Ruiz-del-Olmo, Francisco-Javier; Bustos-Díaz, Javier (2016). “Del tweet a la fotografía, la evolución de la comunicación política en Twitter hacia la imagen. El caso del debate del estado de la nación en España (2015)". Revista latina de comunicación social, n. 71, pp. 108-123.

https://doi.org/10.4185/RLCS-2016-1086

Sander, Sam (2015). "Instagram: The new political war room?”. NPR, September 3.

http://www.npr.org/sections/itsallpolitics/2015/09/03/436923997/instagram-the-newpolitical-war-room

Sartori, Giovanni (1998). Homo videns: la sociedad teledirigida. Madrid: Taurus. ISBN: 950511429 X

Schill, Dan (2012). "The visual image and the political image: A review of visual communication research in the field of political communication". Review of communication, v. 12, n. 2, pp. 118-142.

https://doi.org/10.1080/15358593.2011.653504

Selva-Ruiz, David; Caro-Castaño, Lucía (2017). "Uso de Instagram como medio de comunicación política por parte de los diputados españoles: la estrategia de humanización en la 'vieja' y la 'nueva' política”. El profesional de la información, v. 26, n. 5, pp. 903-915.

https://doi.org/10.3145/epi.2017.sep.12

Slimovich, Ana (2020). "Instagram y política: mediatización y circulación en los perfiles de Cristina Fernández de Kirchner y Mauricio Macri”. Cuadernos del Centro de Estudios de Diseño y Comunicación, n. 112.

https://doi.org/10.18682/cdc.vi112.4101

Soulages, François; San-Ginés-Aguilar, Pedro (2012). Fotografía y poder. Comares. ISBN: 8498369223

Street, John (2016). "Popularization of politics". In: Gianpietro, Mazzoleni (ed.). International encyclopedia of political communication. Wiley-Blackwell, pp. 45-50. ISBN: 9781118290750

Velert, Jordi (2020). Comunicación política en Instagram: Ada Colau, Joan Ribó y Manuela Carmena. Beers \& Politics. ISBN: 9798630585691

Viounnikoff-Benet, Nadia (2017). Narrativa visual del liderazgo político en campaña electoral. Tesis doctoral, Universitat Jaume I.

http://repositori.uji.es/xmlui/handle/10803/454982

WeAreSocial (2018). "Digital in 2018. World's internet users pass the 4 billion mark". WeAreSocial, 30 January.

https://wearesocial.com/blog/2018/01/global-digital-report-2018

WeAreSocial (2019). Digital in 2019. España. WeAreSocial.

https://wearesocial.com/es/digital-2019-espana 